\title{
DE FÁBULAS Y BESTIARIOS: \\ LA ESTÉTICA DE LOS ANIMALES EN LA EDAD MEDIA
}

RICARDO PIÑERO MORAL

Universidad de Salamanca $^{1}$

\begin{abstract}
Resumen:
Los animales en la Edad Media pueden ser considerados como un elemento de sentido que transciende los límites de su condición biológica. Desde el punto de vista filosófico no sólo ofrecen una virtualidad extraordinaria por lo que respecta a su aspecto formal, sino que presentan y representan un conjunto de valores que nos permiten establecer puntos de encuentro entre los diversos ámbitos de la cultura. Arte, teología, literatura, filosofía, biología... tienen en su horizonte la imagen del animal como un referente privilegiado para llegar a comprender el sentido de la realidad y del propio ser humano que la habita. Palabras clave: Estética, animales, Edad Media, bestiario
\end{abstract}

\begin{abstract}
:
The animals in the Middle Ages can be considered an element of sense that overcomes the limits of his biological condition. From the philosophical point of view not only they offer an extraordinary virtuality for what it concerns to his formal aspect, but they present and represent a 'corpus' of values that allow us to establish points of meeting among the diverse areas of the culture. Art, theology, literature, philosophy, zoology... have in his horizon the image of the animal as a modal favoured to manage to understand the sense of the reality and of the human being who lives it.
\end{abstract}

Key words: Aesthetics, animals, Middle Age, Bestiary

\section{DE LA REALIDAD DE LAS BESTIAS AL SENTIDO DE LAS IMÁGENES}

El arte medieval en su conjunto nos ofrece una zoo-teca incomparable. Aquellos que trabajamos directamente con pergaminos y vitelas disfrutamos cada día de ella. No importa si el escenario es un Libro de Horas de tal o cual reina o una copia miniada de la Naturalis Historia de Plinio... Esta presencia de lo animal acaece tanto si el manuscrito pretende ser transmisión de un texto sagrado o un inventario de madura y objetiva ciencia profana. Incluso a veces, el arte medieval es tan poderoso (tan virtual...), que es capaz de unir en una sola miniatura, la muy pura Anunciación de la Virgen María

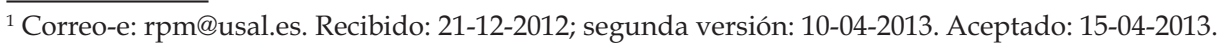


-en cuyo suceso suele aparecer, además, un animal específico, la paloma como Espíritu Santo- con una escena profana en la que un pequeño sátiro -símbolo de la lujuria más profana pensable- toca, displicente y burlón, un laúd ${ }^{2}$. Ahora bien, tal vez si los animales ocuparon los márgenes de los manuscritos ${ }^{3}$ es porque, en realidad, jugaban un papel central en la cultura del medioevo.

El mundo de los animales medievales ${ }^{4}$ es, preferentemente, el mundo de las imágenes de los animales. Éstos están más al servicio didáctico que bajo la mirada del interés científico. Porque su ser 'imagen' les convierte en un tipo especial de entidades. Los hombres del medioevo se los apropian, los devoran al hacer de ellos inteligencia, imaginación, memoria. Los animales en la Edad Media ${ }^{5}$ son más una creación humana que divina, como si la acción adánica de la denominación los hubiera convertido en una posesión más del hombre. En la imagen del animal medieval prima más su construcción simbólica que cualquier otra motivación, ya sea ésta biológica o incluso estética. Aspecto natural y artístico están al servicio de su sentido.

Los textos medievales como Beatos, leyendas, fábulas o bestiarios son el reflejo de una apropiación o si se quiere de una subversión en el mundo de la naturaleza, que tiene como fin el establecimiento de una hermenéutica con un poder especial, consistente en convertir a los animales en espejo de los seres humanos. El pensamiento estético medieval genera, de este modo, una inversus mundi ${ }^{6}$, y si no somos conscientes de ella y no la aplicamos -de la misma manera que un miope utiliza sus lentes- jamás llegaremos a entender aquello que se nos presenta, patentemente, ante nuestros ojos.

Los animales, en cuanto imagen, parece que son directos, inmediatos, pero su presencia ontológica, digamos, no es equivalente a su semántica iconológica. La dificultad de esta inversión del mundo radica en que un ser de apariencia, más o menos similar, puede desplegar diferentes significados según el lugar, la época y, en general, el contexto en el que se sitúa. Del mismo modo que una palabra puede tener varios significados simultáneos o sucesivos, la imagen de un animal puede ser vehículo de ideas y valores no sólo diferentes, sino absolutamente opuestos. Este principio de inversión, que convierte el mundo natural en un complejo y polisémico universo de sentidos, ha de ser tenido en cuenta como un dato previo a la hora de pensar el animal en la Edad Media7.

Una de las inversiones a la vez más extrañas y mejor asumidas por el hombre es que, en las fábulas del medioevo, los animales hablan con toda naturalidad. Transferimos a los animales, apenas sin darnos cuenta, un patrimonio tan exclusivo como el lenguaje.

\footnotetext{
${ }^{2}$ Como puede verse en el Libro de Horas francés, miniado hacia 1475 por Jean Fouquet, que se conserva en la Biblioteca Real de Copenhague, con la signatura Gl. Kgl. Saml. 1610 4º f 40r.

${ }^{3}$ Tesnière, M. H. (2004)

${ }^{4}$ Benton, J. R. (1992)

${ }^{5}$ Salisbury, J. E. (1994).

${ }^{6}$ Cf. Curtius, E. (1973: 94-98)

${ }^{7}$ Cf. Flores, C. (ed.) (1996).
} 
En esa transmisión lingüística se incluye, además, la capacidad de pensar y razonar, de tal manera que cualquiera de los personajes de una fábula no sólo expone de viva voz aquello que desea, sino que además lo hace siguiendo un plan argumentativo preciso, convincente, retórico, en el mejor de los sentidos, pues es capaz de aunar pensamiento y dicción de un modo cualificado. Nadie se extraña del discurso pausado y bien medido de un zorro o de un asno -por poner casos de animales no muy bien vistos por la idiosincrasia de su 'carácter' -, sin caer en la cuenta de que en esa transposición lingüística va, en el fondo, todo el 'genoma' del ser humano, todo aquello que, hasta entonces, nos hacía diferentes a las bestias, todo aquello que nos servía para construir nuestra identidad. Las fábulas humanizan los animales para hacer ver al hombre su propia animalidad.

Los bestiarios no dan la voz a los seres que los pueblan ${ }^{8}$. Todo lo más atribuyen a algunos de ellos la capacidad de hablar, como al loro ${ }^{9}$ tontorrón o a la perversa mantícora ${ }^{10}$. En ellos la puesta en escena cambia. Sustituyen la transferencia lingüística por la icónica. Un bestiario para mostrar la naturaleza de un animal está atado a la imagen, como el personaje de una fábula lo está a su voz. A través de su representación, la bestia nos cuenta cómo es, cómo se comporta, cuáles son sus hábitos, sus gustos, sus miedos; eso sí, lo hace sin abrir la boca. Quienes hablan en un libro de bestias son la imagen y el 'experto' -en su doble condición de naturalista y moralista-, pero lo hacen de una manera muy peculiar: sólo porque los bestiarios antropologizan al animal invierten su mundo-, tras la descripción física pueden sacar consecuencias morales, tanto de su naturaleza como de su comportamiento.

\footnotetext{
“Los historiadores de las ciencias nunca se han preguntado por qué la historia natural no había realizado ningún progreso en la Edad Media. La razón esencial estriba en que los teólogos la sustituyeron por el simbolismo animal. En los escritos medievales, la historia natural, como en las fábulas de La Fontaine, es sólo un capítulo de la moral. No hay ninguna diferencia entre el naturalista y el moralista, porque los animales no se estudian ni en sí ni por sí mismos, sino como esbozos o reflejos del hombre, centro de la Creación, para el cual el mundo animal ofrece un espejo, a la vez de aumento y deformante, de su propia naturaleza, la imagen o la caricatura de sus pasiones, virtudes y vicios" 11 .
}

Así, la Edad Media acoge la naturaleza animal como un punto relevante tanto para la reflexión filosófica como para la representación plástica, haciendo de las bestias un paradigma de comprensión del ser humano que les pone el nombre ${ }^{12}$. Se genera, de este modo una especie de familiaridad ${ }^{13}$ que aportará una vía de análisis de gran riqueza hermenéutica. El universo cultural del medioevo está poblado por infinidad de animales, no sólo por el trabajo fundamental que desempeñan en los trabajos de

\footnotetext{
${ }^{8}$ Payne, A. (1990).

${ }^{9}$ El psittacus que aparece en uno de los bestiarios medievales que se conservan en la Biblioteca Real de Copenhague resulta un ejemplo incuestionable (Gl. Kgl. $16334^{\circ}$, f 33v).

${ }^{10}$ Cf. Rochester Bestiary en la British Library de Londres c. 1230 (Royal MS 12 F xiii).

${ }^{11}$ Réau, L. (2000: 96).

${ }^{12}$ Gl. Kgl. $16334^{\circ}$, f $21 v$.

${ }^{13}$ Délort, R. (1984: 289).
} 
la agricultura, sino también como auténticos compañeros del hombre en otras tareas como la caza, sin olvidar que constituyen una base alimenticia para el ser humano. Pero lo que me interesa mostrar es que la interacción con los animales configura la experiencia del mundo que el hombre posee ${ }^{14}$. La percepción de la naturaleza animal ayudó a los hombres medievales a construir la imagen del mundo y se sirvió de ellos para dotar de un sentido más amplio a su propia condición, como seres creados por un mismo Dios.

Animales reales o imaginarios... una distinción cuya competencia no se funda en su efectividad. Para el naturalista o el moralista, lo fundante de la relación con el animal no es un criterio ontológico de existencia real, sino la relación especular que puede ser trazada entre diferentes tipos de criaturas. El interés no radica en proyectar y financiar una expedición zoológica a Arabia, o a Etiopía, o a las lejanas tierras de la India para comprobar sobre el terreno la existencia de los seres de los que habla un bestiario como el Physiologus, ni en recorrer los mares del sur en busca de sirenas... ${ }^{15}$ La mentalidad medieval prefiere dar por sentada la 'realidad' de esas criaturas porque, existan efectivamente o no, el caso es que poseen una capacidad explicativa extraordinaria.

La literatura medieval, como por otra parte la literatura antigua, está plagada de reflexiones que nos llevan a una especie de etología comparada entre los animales y el hombre. Los cuentos, las narraciones, la poesía, retratan en innumerables ocasiones animales que actúan sobre la sensibilidad y la imaginación, y ofrecen un punto de vista alternativo que termina por presentar el comportamiento de los animales como si fuera el de los seres humano. ${ }^{16}$ Estos retratos comparados están en los claustros de los monasterios, en las fábulas, en los manuscritos miniados, en los sermones de los predicadores, es decir, están al alcance de todos, no importa su condición consagrada o laica, no es relevante el nivel cultural que se tenga, no discrimina entre la riqueza y la pobreza. Su nivel de implantación es tan amplio que a nadie le resulta ajeno establecer un parangón entre él mismo y los animales, entre sí mismo y lo otro de sí.

“Los animales tienen una historia. Pero participan también de la nuestra, porque los símbolos a los que les asociamos desde el albor de los tiempos son testimonio de nuestra propia concepción del mundo"17.

Fábulas, relatos épicos, bestiarios, son todos ellos punto de encuentro entre el hombre y el mundo, entre lo humano y lo animal. Aún más, los animales son el espejo, esa condición de objetivación necesaria a toda reflexión de segundo orden, en la que el factor meramente especular deviene desarrollo especulativo. Los animales se toman como una proyección necesaria que, por un lado, nos distancia de nosotros mismos permitiendo así una contemplación sosegada, distante, separada, pero, por otro, nos rebota, nos redirige la mirada hacia nosotros mismos, como si fuéramos el

\footnotetext{
${ }^{14}$ Baxter, R. (1998).

${ }^{15}$ Gl. Kgl. 1633 4 , f 40v.

${ }^{16}$ Gl. Kgl. 1633 4 , f 10v.

17 Tesnière, M. H.(2005: 10).
} 
auténtico punto de 'reflexión', el punto en el que el ir y venir del pensamiento genera conocimiento. Escrutar la sociedad, sus problemas, el régimen político, la historia, buscar el sentido del mundo... todas esas tareas se cumplen a la perfección en el examen de la relación hombre-animal.

\section{MARÍA DE FRANCIA Y ODÓN DE CHERITON: ANIMALES DE LA COR- TE Y LA IGLESIA}

Si exceptuamos el bestiario, cuando leemos los textos animalísticos medievales, paradójicamente, aprendemos relativamente poco sobre sus características biológicas, pero enseguida vemos lo que esos autores que los escriben pensaban sobre los hombres. A continuación expondré tan sólo dos ejemplos para hacer más sólida la afirmación que acabo de formular. Repasaremos dos compilaciones de relatos esenciales: las fábulas de María de Francia y las de Odón de Cheriton. Lo que les interesa a estos dos fabulistas es reflejar el contexto social de su época, las cuestiones políticas, el statu quo, pero desde dos puntos de vista diferentes respectivamente: la corte y la iglesia, dos colinas privilegiadas, en todos los sentidos, desde las que otear un amplio horizonte.

Estos dos autores comparten el hecho de retratar animales y presentarlos como trasuntos de la condición y del comportamiento humanos, y, además, esos animales que describen se convierten en la manifestación de valores y contravalores precisos, haciendo de la literatura, supuestamente fantástica, una guía de orientación para la realidad, supuestamente existente. Se pueden establecer dos grandes tipos de animales: aquellos que representan los valores más deseados, lo que les convierte en seres respetados y de una dignidad excelente -pongamos por caso el león-; y aquellos otros que son el contrapunto de la excelencia, que reflejan lo no deseado, pero real, del mundo que retratan -por ejemplo los perros-.

Nuestro lenguaje popular es heredero de esa catalogación axiológica. Cuando se quiere halagar la fortaleza, la virtud, la resistencia, la majestuosidad, automáticamente el animal que nos viene a la cabeza es -el lector estará de acuerdo conmigo-, el león. Por el contrario, cuando queremos insultar, injuriar, desprestigiar, rebajar la categoría de alguien, una de las expresiones más comunes incluye una comparación con el perro ${ }^{18}$. Estas vías especulares -que no menos especulativas, a pesar de aparecer fuera de los tratados filosóficos convencionales- se construyen y aplican por extenso en la cultura medieval. Pero veamos las aportaciones de los dos fabulistas mencionados.

María de Francia ${ }^{19}$ es, sin duda, uno de los referentes fundamentales de lo que podríamos denominar un génerofabulístico cortesano.Sufigura noes, lamentablemente, muy conocida. Podemos situarla en el siglo XII, y de cómo están escritos sus textos podemos colegir que tenía una buena formación en los clásicos -conocía sin duda a los autores griegos y romanos-. Probablemente vivió en la Inglaterra normanda y sus obras, tal vez fueran bien leídas en la corte de Enrique II y de su ilustrada esposa

\footnotetext{
${ }^{18}$ Woods, B.A. (1959).

${ }^{19}$ Spiegel, H. (ed. \& trans.) (1987); Cuenca, L. A. de (ed.) (1975).
} 
Leonor de Aquitania. La fecha de producción de sus fábulas puede fijarse entre 1155 y 1189. Todas sus historias (un total de ciento tres, todas en verso) terminan con una moralización y están basadas en las de Fedro y en tradiciones populares. Sobre la autoría no hay duda, pues en el propio texto podemos leer: María es mi nombre y soy de Francia.

Las fábulas de María trascendieron el escenario cortesano e influyeron en otros contextos. Sus relatos están escritos en francés, mientras que los demás relatos de la época lo estaban en latín. Tal vez este dato nos sirva para entender su rápida y buena difusión, pues se conservan un buen número de manuscritos, lo que avala, sin duda, la popularidad de esta colección de fábulas, aunque, bien es cierto que a sus textos se fueron añadiendo otros de diferentes autores ${ }^{20}$. Otro aspecto que facilitó su expansión es la habilidad misma de la autora, capaz de convertir textos clásicos muy firmes y severos, con demasiada verborrea, en relatos muy amenos, muy cercanos, que podían ser tomados como historietas para divertir en la corte, gracias a una particular forma de versificar, lo que revela una gran capacidad artística para presentar escenarios y protagonistas surgidos en épocas muy remotas, y hacerlos parecer adecuados a su momento histórico.

Odón de Cheriton ${ }^{21}$, nacido hacia 1185 en Inglaterra, en el seno de una familia de muy buena posición (Cheriton daba nombre a una de sus posesiones), se orienta hacia la vida consagrada. Es un clérigo que se forma en Inglaterra pero culmina sus estudios doctorándose en teología en la Universidad de París. Es un viajero incansable, recorre Francia y España, y conoce muy bien la vida monástica. Aunque no hay noticia exacta sobre su pertenencia a la orden del Císter, lo cierto es que en su obra -desarrollada en pleno siglo XIII- se detectan algunos aspectos que le podrían vincular con el ideario estético cisterciense, sobre todo en lo que respecta a la lucha contra los abusos y los excesos estéticos y políticos.

Mientras que a María de Francia le interesa ofrecer un espejo cortesano, las fábulas de Odón sirven de reflejo del mundo religioso que le circunda, de la sociedad eclesiástica que le rodea. Si en las fábulas de la autora francesa los animales eran cortesanos, en las del inglés son monjes y clérigos. Aunque uno y otro parten del tronco común de los fabulistas greco-romanos, se separan paulatinamente de ellos mostrando una identidad perfectamente diferenciada con respecto a sus predecesores. Veamos alguna de esas diferencias: en el mundo antiguo Esopo, por ejemplo, utiliza sus personajes como peones de un ajedrez que intentan criticar un orden social dado; el propio Fedro, en el siglo primero de nuestra era, define estrictamente las fábulas como una creación literaria que surge entre los esclavos para poder hablar con toda libertad y criticar todo aquello que consideran injusto.

Tanto en el autor griego como en el romano, los relatos animalísticos lo son como un instrumento encriptado "en el que tiene lugar una enseñanza moral y una sátira

\footnotetext{
${ }^{20}$ Keidel, G. C. (1909)

${ }^{21}$ Jacobs, J. C. (ed.) (1985); Cf. Sánchez Salor, E. (ed.) (1992: 207-276).
} 
social o política"22. Las fábulas de la antigüedad son un vehículo reflexivo a salvo de la censura y de la mirada directa de quien ostenta el poder. Sin embargo, en los siglos XII y XIII, cuando se restauran las fábulas clásicas, el poder civil y la iglesia las usan como un arma capaz de incidir en el comportamiento del pueblo, de la sociedad, de la comunidad. El cambio de perspectiva es evidente: los relatos 'fantásticos' pasan de ser un arma contra el orden establecido a ser un instrumento de ese poder para justificarse, para darse una carta de identidad y para mostrarse como la mejor opción de las posibles. Frente al criticismo clásico, la fábula medieval es una herramienta para mantener el estado presente de las relaciones, un instrumento de autoconservación, en el que, además, se ofrece toda una visión del mundo con unas jerarquías, unos roles, unas creencias y todo un sistema de valores.

En ocasiones, las fábulas de María han sido despreciadas y muy criticadas $^{23}$ por estas razones, porque servían como mecanismos de control del orden social y por haber perdido su capacidad de poner en tela de juicio las conductas de los que lo rigen; pero en todo caso, afirmaciones como éstas son demasiado generales, y en la literatura fabulística medieval también se pueden encontrar vetas de crítica muy fina contra los poderes políticos, las injusticias sociales y las arbitrariedades eclesiásticas, además de una magnífica adecuación de los personajes clásicos a un nuevo contexto.

María de Francia y Odón de Cheriton tal vez tengan una orientación más conservadora que la de Esopo o Fedro, pero tuvieron una capacidad de influencia muy semejante a la de sus predecesores. Fueron capaces de construir relatos que la élite de la cultura empleó para desempeñar sus tareas de gobierno político y religioso. La utilización de fábulas y narraciones se presta perfectamente para mostrar un mundo jerarquizado. Los animales responden muy adecuadamente para poder ofrecer una visión estratificada, ordenada y cualificada del sistema social que se quiera. Su validez es, me atrevería a decir, casi universal y universalizable, y además, cuenta con la ventaja que a la identificación animal el ser humano accede como por naturaleza, es decir, la acepta sin estridencias, como un modo natural de concebir su mundo.

En los cambios que los fabulistas medievales introducen en los relatos animalísticos se constata la transformación que se pretende realizar en la conducta de los hombres desde un punto de vista orgánico, social, comunitario. En una fábula antigua, cada animal representa a un ser humano, sin embargo en los versos de María, cada animal corresponde a un grupo social completo, ya sean estos los propios gobernantes o sus siervos. Un animal fuerte no representa a un individuo fuerte, sino a un tipo de individuo. La perspectiva es siempre globalizadora: el animal deviene tipo humano, no individuo, cada animal refleja el modo de ser de un grupo social: la nobleza, el rico, el siervo de la gleba, el pobre, haciendo posible una transposición de la particularidad del individuo a la totalidad de la clase a la que pertenece. Y es ella, María de Francia, la que decide escribir para un escenario, la corte, que alberga un tipo

\footnotetext{
${ }^{22}$ Tesnière, M. H. (2005: 127).

${ }^{23}$ Blackham, H. J. (1985); Henderson, A. C. (1981).
} 
de personaje, el poderoso, el encargado de organizar jerárquicamente todo un mundo de relaciones.

Este nivel globalizador es también en el que se basan los relatos de Odón. Su 'tipo' es el hombre de iglesia, y sus animales representan los intereses eclesiásticos, de modo paralelo a cómo lo ejecuta, en el ámbito cortesano, la fabulista francesa. Para el de Cheriton el concepto de jerarquía es fundamental, porque a partir de él despliega los caracteres de los personajes ${ }^{24}$. Su mundo es un todo bien ordenado, compacto, en el que toda posible fisura no es más que una amenaza de la que necesariamente hay que liberarse. Si en la corte se defienden valores como el poder y la fortaleza, en el horizonte eclesial serán la integridad y la compasión dos de los baluartes requeridos. Ambos garantizan la lealtad y la continuidad, dos condiciones de posibilidad de la existencia misma de la Iglesia. Desde la integridad y la compasión pueden ser combatidos el vicio, en cualquiera de sus grados, y la hipocresía. No es de extrañar que los predicadores encontraran en estos textos un apoyo de valor incalculable para presentar la religión como un lugar natural para el hombre.

\section{DE LA TAXONOMÍA ZOOLÓGICA A LA AXIOLOGÍA MORAL}

Tras la conversión de lo particular a lo general, de lo individual a lo colectivo, tan sólo restaba ser cautos a la hora de seleccionar los animales que iban a servir de correa de transmisión para los mensajes políticos, en un caso, y religiosos, en el otro. En virtud de la jerarquización, los animales protagonistas de las historias de María de Francia fueron, a su vez, clasificados como ejemplares para un determinado estrato. Había animales de clase alta y animales de clase baja, pero esta clasificación no se refiere a una división social en sentido estricto, sino a una diferenciación moral dentro de un mismo grupo social. En la excelencia, los puestos más elevados en la jerarquía son ocupados, como era de esperar, por el león o el águila. Aún así éstos tienen siempre un antagonista bien definido.

En su descripción del buen rey María lo compara con el águila, mostrando a este ave como un ser magnánimo, glorioso, especialmente valeroso y muy digno. Cualidades todas ellas que ha de poseer un gobernante realmente noble, por su condición social y moral. Por su parte, el león representa también al buen rey, a aquél que ejerce su potestad con magnanimidad y justicia, representa a la nobleza por su rango 'natural'. Pero, como contra-símbolo, el rey injusto, despiadado, que se aprovecha con malas

\footnotetext{
${ }^{24}$ Uno de los casos en los que la jerarquía se tematiza de manera más explícita es el de la fábula Sobre la cigüeña y el lobo: "Una vez un lobo estaba casi ahogado con un hueso. Buscó un médico. Le dijeron sus siervos: <<La cigüeña tiene un largo pico y podrá sacar el hueso de la garganta.>> Mandó buscar a la cigüeña, prometiéndole una gran recompensa. Vino la cigüeña y le sacó el hueso. Ella pidió la recompensa. El lobo no le quiso dar nada, diciéndole: << ¿Acaso no pude matarte, cuando tenías tu cabeza metida en mi boca? ¿No te es suficiente que te haya dejado seguir viviendo?>> De la misma forma, los campesinos y pobres, cuando sirven a alguien, no pueden esperar ninguna recompensa. Dice, en efecto, el señor: <<El hombre es mío; ¿no es ya mucho no desollarte y dejarte vivir?>>” (Sánchez Salor, E. (ed.) (1992: 228).
} 
artes de sus súbditos tiene como imagen al lobo, un animal malvado, glotón, asesino y terrorífico como pocos.

Entre los antagonistas más renombrados en las fábulas medievales encontramos al zorro $^{25}$, un animal cuya popularidad atraviesa los relatos y los siglos. Como predador representa un status social elevado. Ciertamente no tiene la fuerza del león ni la ferocidad del lobo, pero su astucia lo convierte en un paradigma de especial interés en la explicación de la naturaleza humana. Para ser cazado se requieren muchos perros que sigan su difícil rastro. Su ingenio es inmenso, y queda bien plasmado en las fábulas, en los relatos épicos y en los bestiarios. María de Francia lo menciona en once de sus historias moralizadas en las que nos lo presenta como un icono de del mal, de la pobreza, del engaño y de la hipocresía.

La jerarquización social, política y religiosa, entre poderosos y súbditos, entre predadores y presas, no puede obviar la incorporación en el relato el punto de vista de las víctimas. Si bien es cierto que el interés medieval -y el número de páginas es un dato que lo corrobora- se centra más en el poderoso, también las víctimas aparecen en escena, aunque sea de manera marginal. Entre ellas, el gallo, el cordero, el asno, el perro... De ellas siempre se nos ofrece una opinión muy desfavorable, se retratan, muchas veces, como criaturas estúpidas, ingenuas y la propia fabulista las desacredita, sobre todo, cuando intentan progresar en el orden social establecido. En las fábulas de la poetisa francesa los cambios de clase son impensables, y, no sé hasta qué punto, indeseables.

La perspectiva de Odón respecto a las víctimas es diferente, tal vez por su innegable orientación pastoral ${ }^{26}$, lo que le impide tratar con desdeño a los pobres y a los menos favorecidos. Su interés, por el contrario, está en mostrar sus cualidades, unas virtudes de las que carecen, por lo general, todos aquellos cercanos a las riquezas -como nos recuerda, por ejemplo, el personaje que ocupa el centro en la representación del infierno del Beato de Silos en tetralóbulo-. Incluso hace un examen muy fino de las relaciones de servidumbre, como queda bien ejemplificado en una de sus fábulas en

\footnotetext{
${ }^{25}$ Odón identifica, en varias ocasiones, al zorro con el diablo. Destaca cómo es especialmente astuto su comportamiento incluso cuando se enfrenta al lobo, como en Sobre la zorra, el lobo y el cubo del pozo. El relato Sobre los engaños de la zorra y del gato marca la diferencia entre los que, para librarse del mal suben hacia lo alto -los fieles, representados, en esta ocasión por el gato-, y los que sólo quieren embaucar con sus ardides -los zorros- cuyo final es ser devorados por los perros del cazador. En Sobre la zorra compara su táctica de caza haciéndose la muerta, con la forma en que el diablo se finge muerto para atrapar las almas de los pecadores. De este comportamiento ladino y fraudulento da cuenta Sobre el engaño de la zorra, donde vemos cómo se camufla poniéndose una piel de cordero para meterse entre las ovejas y así saciar sus apetitos.

${ }^{26}$ La orientación pastoral y la defensa del hombre justo está magníficamente reflejada cuando narra los peligros que le acechan cuando se enfrenta al diablo, como en la fábula Del ave que se llama quebrantahuesos: "Hay un ave que se llama quebrantahuesos, freinos, porque con su pico quebranta los huesos y se come el sebo y el tuétano. Cuando por su dureza no puede romperlos, los lleva a lo alto y los deja caer sobre las rocas; y así los huesos se rompen. Así hace el diablo: cuando no puede romper a un hombre firme, le lleva a las alturas de los cargos y entonces le deja caer; así lo destroza totalmente; y cuanto más alto es el cargo, tanto más grave es la caída. El recorrido de una piedra es mayor cuando cae de lo alto que cuando cae de lo bajo. Así, los malvados reyes, los perversos obispos y los ricos sufren una caída mayor desde lo alto hasta el infierno que los pobres" (Sánchez Salor, E. (1992: 229).
} 
las que se narran las peripecias de un macho cabrío y un asno: la cabra engaña al asno para que sea su sirviente, éste se da cuenta y la aplasta:

"un macho cabrío se hizo una vez siervo de un asno y le vio sencillo y humilde. Subió encima del asno y pretendió cabalgar en él. El asno, airado, levantó las patas delanteras y cayó sobre la espalda del macho cabrío, y le aplastó y mató, diciendo: <<Aunque tu dueño sea un asno, no cabalgues sobre él.>> De igual forma, muchos ven a sus dueños sencillos, o ancianos, o ciegos o inhábiles; y les desprecian y se ríen de ellos" ${ }^{27}$.

La moraleja revela qué les sucede a los que no respetan a sus señores, sobre todo si fundan su relación en el engaño y en la burla. Qué forma tan sencilla de explicar las consecuencias de la rebelión del Adversario contra Dios ${ }^{28}$.

Pero la víctima por excelencia de los relatos medievales es el cordero. Cristo nacido como Cordero de Dios es sacrificado. Si Él, que es Dios, bajo la advocación de cordero, es inmolado, qué no le cabe esperar -temer- a aquellos que también son corderos, pero cuyo señor no el Señor. Cristo es, además, el Buen Pastor que atiende, cuida y da la vida por su rebaño. Por una lado, el simbolismo del cordero mantiene la excelencia de ser un sacrificio de redención para la humanidad, y el cristianismo medieval despliega como en ninguna otra época la virtualidad de esta imagen, basta con ver el tratamiento que de ella ofrecen, por ejemplo, San Francisco -cuya relación de empatía con los animales es bien conocida-, y San Buenaventura -que escribe con gran sensibilidad sobre la simbología de las Sagradas Escrituras-.

Si el papel natural del héroe en la literatura medieval era el de predador -el león y el águila ${ }^{29}$ lo son-, el papel de víctima estaba reservado para los perdedores. La única excepción es el cordero, cuando es el Cordero de Dios; una víctima, sí, pero que representa la máxima heroicidad y que posibilita la salvación de la humanidad. El combate entre lobos y corderos reproduce el combate del Maligno contra el Redentor, la lucha de las bestias del infierno contra los ángeles del cielo. María y Odón reflejan también este combate, en la corte y en la Iglesia, dos mónadas con puertas y ventanas desde la que se puede contemplar la realidad del mundo, aunque sea a partir de seres que no existan realmente, o que sean habitantes de otros reinos.

Las fábulas medievales, en realidad, nos ponen en el camino de examinar la sociedad, la justicia, el pensamiento, la religión, la civilización al completo; incluida la propia imagen especular del hombre, es decir, la propia visión del hombre sobre sí mismo, a la luz de un universo de criaturas creadas por el inmenso poder de Dios. A

\footnotetext{
${ }_{27}$ Sobre el macho cabrío a caballo, Ibíd., Sánchez Salor, E. (1992: 274).

${ }^{28}$ Cf. Piñero, R. (2005).

${ }^{29}$ Hemos de llamar la atención sobre el hecho de que estos dos animales tienen una ambivalencia contrastada en las fábulas de Odón, es decir, unas veces representan a Dios y otras al diablo. Se puede constatar, por ejemplo, cómo en el relato titulado Sobre la corneja el águila representa al rey justo, a Dios, mientras que en Sobre la tortuga y el águila ésta representa al mismísimo diablo. Así pues, la tarea hermenéutica ha de ser desarrollada con cautela, analizando cuidadosamente el sentido de cada animal en cada una de las fábulas. No cabe, por tanto, una interpretación global dado que nos conduciría a errores graves.
} 
Odón de Cheriton le obsesionaba justamente esa visión de Dios todopoderoso ${ }^{30}$, como una vía para comprender la realidad. Sus diseños alegóricos inciden justamente en ese intento de desvelar la naturaleza de las criaturas para evitar el error que nos hace caer en el abismo del infierno ${ }^{31}$.

En su arquitectónica literaria el fundamento no es la zoología, sino la Escritura, no olvidemos que era doctor en teología por la Universidad de París. Su creatividad no responde tan sólo al interés por el ejercicio artístico-literario, sino que se inserta en el intento de esclarecer la mente de los hombres para que conozcan los planes de Dios, y entablen un combate contra el diablo. Por eso nos habla de escarabajos ${ }^{32}$, de zorros, de $_{\operatorname{sapos}^{33}}$, transformando el juego literario en un servicio religioso en el que se intenta enseñar a discriminar el bien del mal, la verdad de la falsedad, el vicio de la virtud, el engaño del embaucador de la buena nueva del Cordero. Así escribe en la fábula titulada Sobre el engaño de la zorra:

“La zorra era tan conocida por las ovejas que éstas se guardaban mucho de ella, de forma que no salían de su redil ni se apartaban del perro que las guardaba. Pensó la zorra: <<Sé qué hacer; me pondré una piel de oveja y me introduciré entre las ovejas; entonces podré, aprovechando la ocasión, comer corderos y ovejas. >> Y así lo hizo. Así son muchos religiosos que tienen vestidos blancos de manera que parecen ovejas de Cristo. Estos son los falsos profetas que vienen con la piel de oveja, pero que por dentro son los lobos rapaces y zorras fraudulentas. Tales son los falsos monjes, los falsos predicadores, los falsos religiosos, que no buscan otra cosa de los ricos sino tierras, viñas, dinero y molestan a los que están a su lado más que a ningún otro. Por eso, yo prefiero tener por vecino a un pagano o a un judío antes que a un religioso así. Si yo creyera que los vestidos blancos me santifican, colgaría sobre mi cuello todo lo blanco que pudiera" ${ }^{\prime \prime 4}$.

La popularidad de las fábulas en la Edad Media y la definición ejemplar de los animales ayudó, de manera formidable, a la difusión no de simples narraciones, atractivas y sencillas de comprender, sino a la expansión de un modo de ver el universo y de contemplar el lugar que en él ocupa el ser que dio nombre a todos los animales. Los bestiarios, de este modo, se convierten en 'humanarios', y las fábulas en creaciones que nos permiten soñar con un mundo en el que nuestra capacidad de creación, nuestros deseos y nuestra libertad se realizan, es decir, pasan de la ficción a la existencia.

\footnotetext{
${ }^{30}$ En Sobre el hereje y la mosca Odón enseña que negar el poder creador de Dios no sólo es una herejía, sino que supone una destrucción total del apóstata.

${ }^{31}$ Como en Sobre las quejas de las ovejas al león contra el lobo, o Sobre los asnos vestidos con piel de león, o Sobre el ajedrez, o Sobre la mosca y la hormiga, y, sobre todo, en Sobre la búsqueda de la eterna felicidad por parte de Godero.

32 “De igual forma que el escarabajo bate sus alas ruidosamente, dando la impresión que dice: Frai bien, frai bien; y a la postre choca con tu rostro. Así dicen algunos: Frai bien, frai bien; prometen ungüentos y dan tormento; prometen rosas y dan ortigas" (Sobre el escarabajo, Sánchez Salor, E. (ed.) (1992: 226). Del escarabajo Odón dice, además, que es una criatura maldita y antinatural, porque "le sabe mejor el estiércol del pecado que Cristo, los lugares del diablo y el estiércol [...] que la vida y los ejemplos de los santos" (Sobre un escarabajo: 243), y termina haciendo referencia al Comentario a los Salmos de San Agustín -30, 2- cuando los compara con aquellos que tienen corrompido el paladar de su alma a causa de su fiebre de iniquidad.

${ }^{33}$ Sobre el sapo y la rana es una exposición directa y demoledora sobre el comportamiento de los avaros y los tacaños.

${ }^{34}$ Sánchez Salor, E. (1992: 257).
} 


\section{BIBLIOGRAFÍA}

Baxter, R. (1998): Bestiaries and their Users in the Middle Ages, Phoenix Mill.

Benton, J. R. (1992): The medieval menagerie: animals in the art of middle ages, New York.

Blackham, H. J. (1985): The Fable as Literature, London.

Cuenca, L. A. de (ed.) (1975): Lais. María de Francia, Madrid.

Curtius, E. (1973): European Literature and the Latin Middle Ages, Princeton: 94-98.

Délort, R. (1984): Les animaux ont une historire, Paris.

Flores, C. (ed.) (1996): Animals in the Middle Ages, New York-London.

Henderson, A. C. (1981): "Animal Fables a Vehicles of Social Protest and Satire: Twelfth Century to Henryson", en Goossens, J. \& Sodmann, T. (eds.) Third International Beast Epic, Fable and Fabliau Colloquium, Köln.

Jacobs, J. C. (ed.) (1985): The Fables of Odo of Cheriton, Syracuse.

Keidel, G. C. (1909): "The History of the French Fable Manuscripts", en Publications of Modern Language Association, 24 (1909): 218.

Payne, A. (1990): Medieval Beasts, London.

Piñero, R. (2005): Las bestias del infierno, Salamanca.

Réau, L. (2000): Iconografía del arte cristiano. Introducción general, Barcelona, vol. I: 96.

Salisbury, J. E. (1994): Animals in the Middle Ages, New York.

Sánchez Salor, E. (ed.) (1992): Fábulas latinas medievales, Madrid.

Spiegel, H. (ed. \& trans.) (1987): Marie de France: Fables, Toronto.

Tesnière, M. H. (dir.) (2004): Bestiaire au moyen âge: les animaux dans les manuscrits, Paris.

Tesnière, M. H. (2005): Bestiaire médiéval, Paris.

Woods, B.A. (1959): The Devil in Dog Form. A Partial Type-Index of Devil Legends, Berkeley. 